\title{
Synthesis, electrochemical and spectroelectrochemical studies of metal-free 2,9,16,23-tetraferrocenylphthalocyanine
}

\author{
Z. Jin, K. Nolan, C.R. McArthur, A.B.P. Lever and C.C. Leznoff \\ Department of Chemistry, York University, North York, Ont. M3J IP3 (Canada)
}

\begin{abstract}
Cyclic voltammetric, differential pulse voltammetric and spectroelectrochemical methods have been used to study the newly synthesized metal-free 2,9,16,23-tetraferrocenylphthalocyanine in dichloroethane. Two reversible reduction peaks are obtained, corresponding to electrode reactions of the phthalocyanine ring. The multiple ferrocenyl redox centers are oxidized at one potential. The electronic spectra are reported for this species in different oxidation states.
\end{abstract}

Key words: Iron; Phthalocyanine; Ferrocene; Electrochemistry; Spectroelectrochemistry

\section{Introduction}

Interest in the chemistry of phthalocyanines as homogeneous and heterogeneous catalysts in a wide range of chemical reactions continues to grow [1-5]. Phthalocyanines are used in the electrocatalytic reduction of molecular oxygen and carbon dioxide, in sensors, electrochromic devices [6-10], conducting polymers [11-12] and batteries [13-14] etc.

The utility of the phthalocyanine species in these many applications arises primarily from their redox versatility, intense color, overall chemical and thermal stability, and non-toxicity. We report here an attempt to improve the redox versatility of these species by binding a redox active moiety to the phthalocyanine ring, in this case by attaching four ferrocene groups, forming 2,9,16,23-tetraferrocenylphthalocyanine(II) ( TFCPC $(-2) \mathrm{H}_{2}$ ). In fact, four isomers will be present, arising from the two alternate substitution sites in each benzene ring, for the ferrocene group. These isomers have properties which were not distinguishable by the methods utilized, and we were unable to separate them by chromatography.

Ferrocene units couple together when separated by a short bridge, 1-8 atoms or so [15-17], exhibiting a

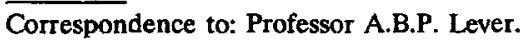

splitting of the $\mathrm{Fc}^{+} / \mathrm{Fc}$ redox process; however they frequently behave independently (uncoupled) at longer separations [18-24]. Thus several different tris(diferrocenylbipyridyl)ruthenium species [25], a range of macrocyclic species with two or more pendant ferrocene moieties [21-24], and some ferrocene substituted pyridine and salicylic acid derivatives [26] have been reported. In these cases, all the ferrocene units oxidized at essentially the same potential; there must actually be a statistical effect [27] which separated the individual $E_{1 / 2}$ to a small degree, but this separation is not usually resolved.

An apparent exception is the meso-tetraferrocenylporphyrin [19] which forms a mixed valence species with $3 \mathrm{Fe}^{\mathrm{III}}$ and $1 \mathrm{Fe}^{\mathrm{II}}$ bis(cyclopentadienyl) units. The existence of such mixed valence species indicates an electronic interaction between the bis(cyclopentadienyl)iron units. Moving the ferrocene units further out from the porphyrin ring, by a conjugated benzene ring, in meso-tetrakis(4-ferrocenylphenyl)porphyrin led to the more common situation where all four ferrocene units were again oxidized at a common potential (at $c a$. $0.54 \mathrm{~V}$ vs. SCE) [18]. Kadish et al. [20] published data for an interesting bis(ferrocenyl)germanium octaethylporphyrin which does show a splitting of ferrocene oxidation potentials of $0.18 \mathrm{~V}$, but in this case the two ferrocene units are bridged by a single germanium atom. 


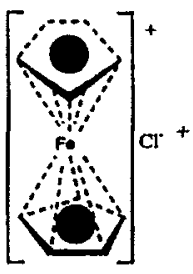

2

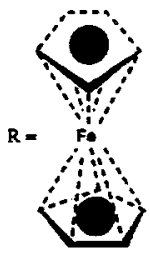

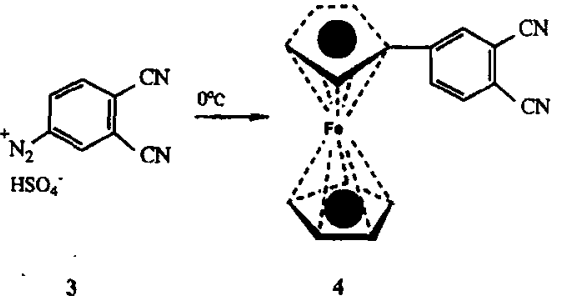

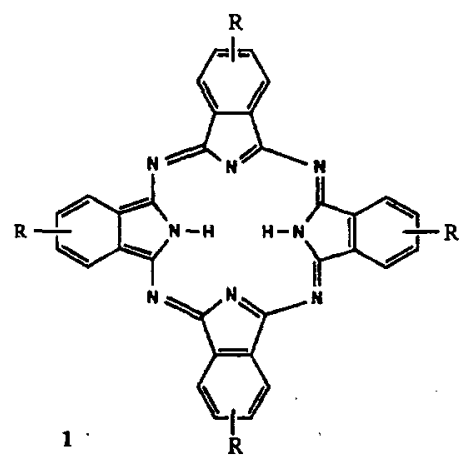

Scheme 1.

Thus, it would appear that ferrocene units at sites more than about four atoms separate from one another do not interact even when there is an apparent conjugated pathway linking them. However given the observation of an exception to the rule in the form of meso-tetraferrocenylporphyrin, there appeared to be merit in exploring the phthalocyanine species.

The electrochemical and spectroelectrochemical properties of (metal-free) $\mathrm{TFcPc}(-2) \mathrm{H}_{2}$ are reported here, but disappointingly; this species also shows a single oxidation wave for oxidation of all four ferrocene units.

\section{Experimental details}

\subsection{Reagents}

Freshly distilled 1,2-dichloroethane (DCE, laboratory reagent, BDH chemicals) was used. Tetrabutylammonium hexafluorophosphate (TBAPF $_{6}$, Aldrich Chemical Company) was dried under vacuum. The DCE solutions containing $\mathrm{TFcPc}(-2) \mathrm{H}_{2}$ for electrochemical study were saturated with nitrogen or argon gas.

\subsection{Preparation of 1-(3,4-dicyanophenyl)ferrocene (4)}

Using a method previously described for the preparation of phenylferrocene [28], ferricenium chloride (2) reacted with 4-diazoniumphthalonitrile bisulfate (3) [29] to give 1-(3,4-dicyanophenyl)ferrocene (4). Compound (4) was thus prepared by dissolving ferrocene $(3.3 \mathrm{~g}$,
$0.017 \mathrm{~mol}$ ) in anhydrous diethyl ether (30 mL), followed by oxidation by the addition of ferric chloride/ diethyl ether. The reaction was stirred for $30 \mathrm{~min}$ and then extracted with water until all the ferricenium chloride (2) had been removed. To this aqueous solution was then added a further aliquot of ferrocene ( 300 mg). A mixture of 4-diazoniumphthalonitrile bisulfate (3) in $5 \mathrm{M}$ sulfuric acid, prepared from 4aminophthalonitrile [29] $(3.3 \mathrm{~g}, 0.023 \mathrm{~mol})$ was added dropwise to the ferrocene/ferricenium chloride solution at $0^{\circ} \mathrm{C}$. After addition was complete, the reaction was stirred for an additional $3 \mathrm{~h}$ at $0^{\circ} \mathrm{C}$. A precipitate, collected on a glass frit was washed with aqueous sodium carbonate, and then dried and pre-absorbed onto classical silica gel. A classical silica-gel column was then run using benzene as the eluting solvent. The first fraction, ferrocene, was followed by a blood-red fraction which gave $3.1 \mathrm{~g}$ of a mixture of 4 and phthalonitrile. The solvent system was then changed to acetonitrile : benzene $(1: 10)$ yielding a dark-red fraction which likely contained a mixture of a disubstituted ferrocene and 3,4,3',4'-tetracyanobiphenyl [28]. The first fraction was further purified on a classical silica-gel column using ethyl acetate : petroleum ether $\left(30-60^{\circ} \mathrm{C}\right)$ (25: 100$)$ as eluant yielding $4(2.4 \mathrm{~g})$. Recrystallization from ethyl acetate/hexane yielded pure 4 (Yield, $2.4 \mathrm{~g}$; $45 \%$ ),mp. $167-168^{\circ} \mathrm{C}$; ms $m / z 312 ;{ }^{1} \mathrm{H}$ NMR (acetone $\left.\mathrm{d}_{6}\right): 4.1$ (s, $5 \mathrm{H}$, ferrocene); 7.89 (d, $\left.1 \mathrm{H}\right) ; 8.8$ (dd, $\left.1 \mathrm{H}\right)$; 8.17 (d, 1H) ppm. Anal. Found: C, 69.41; H, 4.31; N, 9.13; Fe, 17.27. $\mathrm{C}_{18} \mathrm{H}_{12} \mathrm{FeN}_{2}$ calcd: C, 69.26; H, 3.88; $\mathrm{N}, 8.97 ; \mathrm{Fe}, 17.89 \%$.

\subsection{Synthesis of TFCPc(-2) $\mathrm{H}_{2}$ (I)}

A method similar to that of Linstead and coworkers [30] was used to synthesize 1. To dry amyl alcohol (5 $\mathrm{mL}$ ) was added lithium metal $(20 \mathrm{mg})$ which was dissolved at $80^{\circ} \mathrm{C}$ under argon until a turbid solution was observed. At this point $4(250 \mathrm{mg})$ was added, and the reaction mixture heated to $125^{\circ} \mathrm{C}$ under argon. After 3 $h$, the dark-blue reaction mixture was allowed to cool, diluted with hexane and filtered on a glass frit. The precipitate was dissolved in chloroform, and the filtrate collected. After solvent removal, the resulting crude dilithium tetraferrocenylphthalocyanine was demetallated by dissolving the dilithium salt into absolute ethanol $(10 \mathrm{~mL})$ containing $1 \mathrm{M} \mathrm{HCl}$ acid $(0.5 \mathrm{~mL})$ and was allowed to stand for $2 \mathrm{~h}$. A blue precipitate, collected by centrifugation, was pre-adsorbed onto classical silica gel for flash silica column chromatography using chloroform as the eluting solvent. The first band was dark-blue, and gave TFcPc $(-2) \mathrm{H}_{2}(32 \mathrm{mg}$, $32 \%$ ) which was re-precipitated from chloroform and hexane. FAB mass spectrometry exhibited the expected $\mathrm{M}+1$ parent ion for $\mathrm{TFcPc}(-2) \mathrm{H}_{2}$ (1) at 1251. Anal. 
Found: $\mathrm{C} 68.32, \mathrm{H} 4.23, \mathrm{~N} 8.64 \%$. $\mathrm{C}_{72} \mathrm{H}_{50} \mathrm{Fe}_{4} \mathrm{~N}_{8}$ calcd.: C 69.14, H 4.03, N 8.96\%.

\subsection{Physical methods}

Electronic spectra were recorded with a Guided Wave Inc. Model 100-20 Optical Waveguide Spectrum Analyser.

Electrochemical experiments were carried out at room temperature $\left(20^{\circ} \mathrm{C}\right)$, and the data were collected using the traditional three-electrode system. A platinum wire electrode $3 \mathrm{~mm}$ in length, $0.5 \mathrm{~mm}$ in diameter, or a platinum disk electrode $(d=0.127 \mathrm{~mm})$ were used as working electrodes, while a large area platinum wire electrode was used as an auxiliary electrode. A potassium chloride saturated SCE was used as a reference electrode. Cyclic voltammetric and differential pulse voltammetric data were collected with a Model CYSY-1 Computer Controlled Electroanalysis System (Cypress Systems, Inc.), or with a Princeton Applied Research PARC 174A Polarographic Analyzer.

\subsection{Spectroelectrochemistry}

A thin-layer spectroelectrochemical cell was fabricated similar to the design described by Lin and Kadish [31]. These experiments were carried out using a PARC 370 electrochemical system, with a PARC-173 potentiostat and a PARC-175 wave form generator to control the potential of the platinum grid working electrode. A sealed large area platinum plate electrode was used as an auxiliary electrode. The electronic spectra of $\mathrm{TFcPc}(-2) \mathrm{H}_{2}$ in different oxidation states were recorded in a nitrogen-saturated DCE solution containing $0.02 \mathrm{mM} \mathrm{TFCPc}(-2) \mathrm{H}_{2}$ and $0.1 \mathrm{M} \mathrm{TBAPF}_{6}$. $\mathrm{TFCPC}(-2) \mathrm{H}_{2}$ was oxidized or reduced potentiostatically.

\section{Results and discussion}

\subsection{The electrochemistry of $\mathrm{TFCPC}(-2) \mathrm{H}_{2}$ in DCE solu-} tion

Figure 1 shows the $\mathrm{CV}$ curve of $c a .0 .05 \mathrm{mM}$ TFCPC $(-2) \mathrm{H}_{2}$ in nitrogen-saturated DCE solution containing $0.1 \mathrm{M} \mathrm{TBAPF}_{6}$ as supporting electrolyte on a platinum wire electrode at a scan rate of $200 \mathrm{mV} \mathrm{s}^{-1}$. Two reversible reductions (couples I and II) are observed at $E_{1 / 2}=-0.79$ and $-1.14 \mathrm{~V}$ vs. SCE (Table 1). The difference in half-wave potential between the first and second reductions of TFcPc $(-2) \mathrm{H}_{2}$ is $0.35 \mathrm{~V}$, which compares to an average separation of $0.35 \pm 0.05$ $\mathrm{V}$ for the first and second reduction processes of metal-free phthalocyanine [32-34] at the phthalocyanine $\pi$-ring system. These two couples are unequivocally assigned [32-34] to successive ring reduction processes, namely, I, TFcPc $(-2) \mathrm{H}_{2} /\left[\mathrm{TFcPc}(-3) \mathrm{H}_{2}\right]^{-}$and

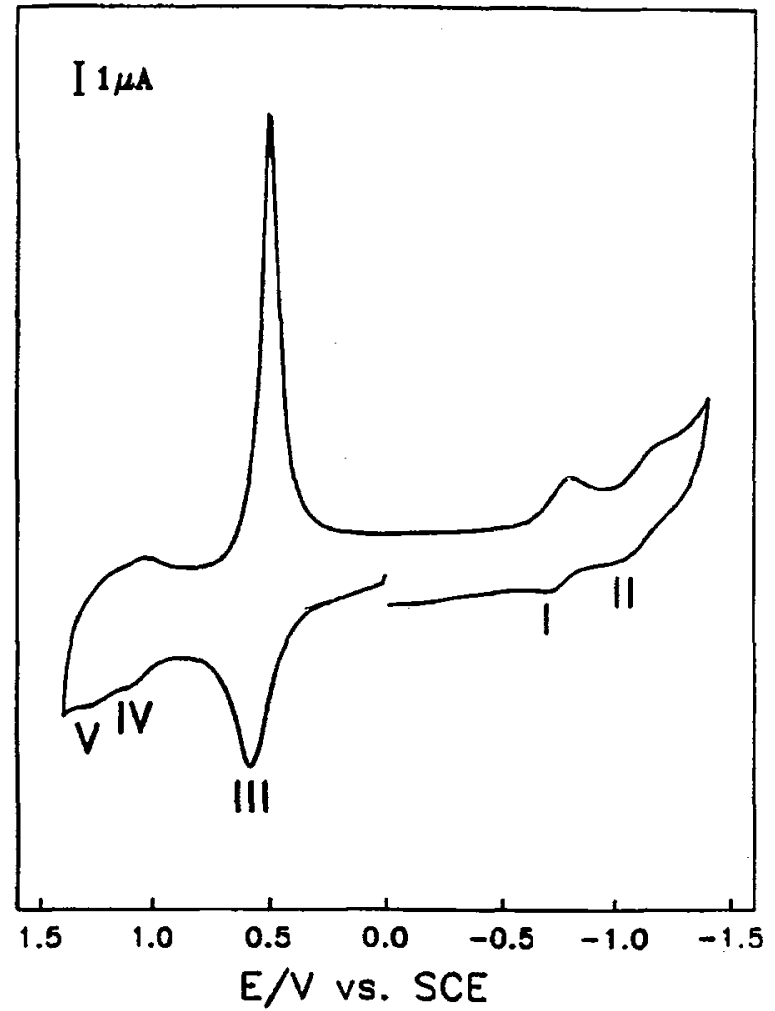

Fig. 1. CV curve of TFcPd -2$) \mathrm{H}_{2}$ in DCE. Scan rate: $200 \mathrm{mV}^{-1}$, $0.1 \mathrm{M} \mathrm{TBAPF}_{6}$ as supporting electrolyte, the concentration of $\mathrm{TFcPc}(-2) \mathrm{H}_{2}$ is $c a .0 .05 \mathrm{mM}$. A platinum wire electrode served as a working electrode.

II, $\left[\mathrm{TFcPc}(-3) \mathrm{H}_{2}\right]^{-} /\left[\mathrm{TFcPc}(-4) \mathrm{H}_{2}\right]^{-2}$ respectively. The first reduction potential lies between that of unsubstituted $\mathrm{Pd}(-2) \mathrm{H}_{2}$ and that of tetraneopentoxyphthalocyanine $\operatorname{TNPc}(-2) \mathrm{H}_{2}[33,34]$ suggesting that the effect of the ferrocene units is to transfer some small amount of additional charge density to the ring, relative to a hydrogen atom.

As shown in Fig. 1, this solution of TFcPc $(-2) \mathrm{H}_{2}$ displays one prominent oxidation couple (III), with a sharp cathodic component, $E_{\mathrm{p}, \mathrm{c}}=0.49 \mathrm{~V}$, and a welldefined anodic component, $E_{\mathrm{p}, \mathrm{a}}=0.57 \mathrm{~V}$ (CV expt. at $200 \mathrm{mV}^{-1} \mathrm{~s}$ scan rate). The cathodic wave for III (Fig.

TABLE 1. Electrochemical data for $\mathrm{TFCPC}(-2) \mathrm{H}_{2}$ in DCE, $V$ es. SCE

\begin{tabular}{lcl}
\hline Couple & $E_{1 / 2}(\mathrm{~V})$ & Assignments \\
\hline I & -1.14 & {$\left[\mathrm{TFcPc}(-3) \mathrm{H}_{2}\right]^{-1} /\left[\mathrm{TFcPc}(-4) \mathrm{H}_{2}\right]^{-2}$} \\
II & -0.79 & $\mathrm{TFcPc}(-2) \mathrm{H}_{2} /\left[\mathrm{TFcPc}(-3) \mathrm{H}_{2}\right]^{-1}$ \\
II & 0.52 & {$\left[\mathrm{TFc}^{+} \mathrm{Pc}(-2) \mathrm{H}_{2}\right]^{+4} / \mathrm{TFcPc}(-2) \mathrm{H}_{2}$} \\
IV & 1.05 & {$\left[\mathrm{TFc}^{+} \mathrm{Pc}(-1) \mathrm{H}_{2}\right]^{+5} /\left[\mathrm{TFc}^{+} \mathrm{Pc}(-2) \mathrm{H}_{2}\right]^{+4}$} \\
V & 1.12 & \\
\hline$E_{1 / 2}$ values were obtained by differential pulse voltammetry at a \\
scan rate of $5 \mathrm{mV} \mathrm{s}^{-1}$.
\end{tabular}


1) has a shape clearly indicative of a desorption wave. Evidently the oxidation product at couple III is insoluble and deposits on the electrode. As the switching upper potential becomes more positive, the cathodic current of couple III increases, but the anodic current is unaffected. The apparently large cathodic current arises from both faradaic and capacitative sources. The amount of deposition increases with the time the electrode remains polarized positive or couple III. Because the oxidized material which is deposited, re-dissolves very rapidly upon reduction, the anodic scan is unaffected. This is confirmed by the very large $i_{\mathrm{p}, \mathrm{c}}: i_{\mathrm{p}, \mathrm{a}}$ ratios at slow scan rates (Fig. 2). There is less time for deposition of $\left[\mathrm{TFcPc}(-2) \mathrm{H}_{2}\right]^{4+}$ at high scan rates, and the ratio $i_{\mathrm{p}, \mathrm{c}}: i_{\mathrm{p}, \mathrm{a}}$ decreases towards 1.0 , see $\mathrm{CV}$ data collected at $10 \mathrm{~V} \mathrm{~s}^{-1}$ (Fig. 3). The insolubility of species containing multi- $\mathrm{Fc}^{+}$units has been previously noted [18]. We were unable to find a solvent where the oxidation product was soluble.

The ratios of the anodic peak current, and charge under couple III to the cathodic peak current and charge of the one-electron couple I are 3.7 and 4 respectively.

A concerted four-electron process is extremely rare, and would, if present, have demonstrated a current ratio of 8 (CV current proportional to $n^{3 / 2}$ [35]). Here it is much more likely that we deal with four indepen-

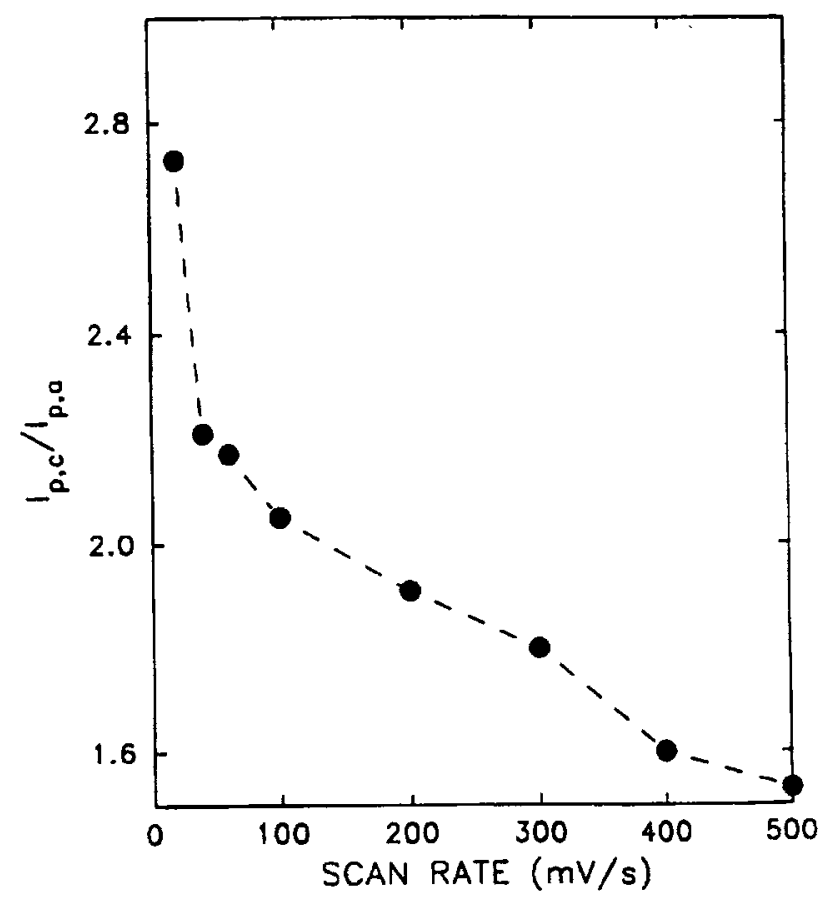

Fig. 2. The effect of scan rate on the peak current ratio $I_{\mathrm{p}, \mathrm{c}}: I_{\mathrm{p}, \mathrm{a}}$ of couple III.

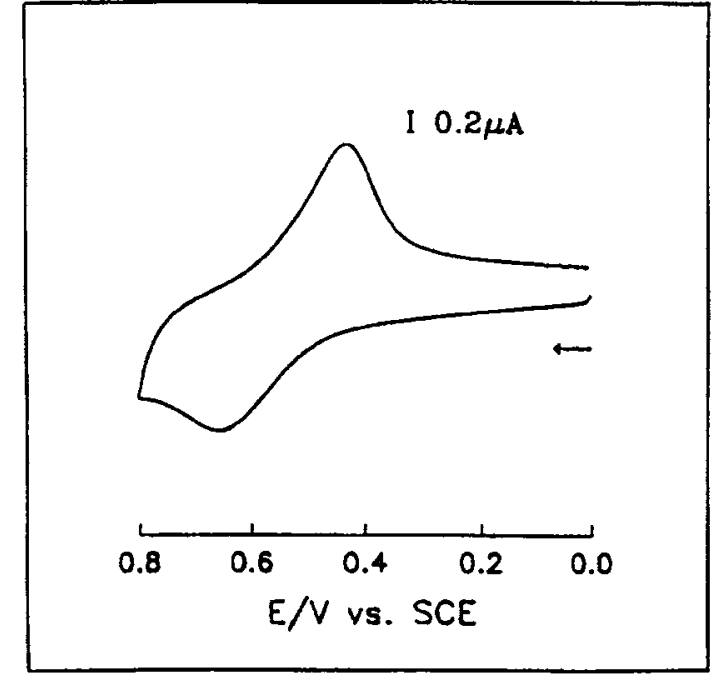

Fig. 3. CV curves of $\mathrm{TFcPc}(-2) \mathrm{H}_{2}$ at fast scan rate. Scan rate: 10 $\mathrm{V}^{-1}$; Platinum disk electrode: $127 \mu \mathrm{m}$.

dently diffusing one-electron processes which, however, are occurring on the same molecule. This would give rise to an anodic III/cathodic I current or charge ratio of 4 , assuming similar rate constants. The data agree more closely to this than to the concerted case.

Further, the potential of this process is in the region anticipated for ferrocene oxidation $[18,19,25,36]$ leading to its unequivocal assignment to the "simultaneous" oxidation of four uncoupled ferrocene moieties.

Differential pulse voltammetry of $\mathrm{TFcPc}(-2) \mathrm{H}_{2}$ or DPV data at $5 \mathrm{mV}^{-1} \mathrm{~s}$ (peak III, forward positive scan $0.49 \mathrm{~V}$ (half-peak width $120 \mathrm{mV}$ ) and reverse scan 0.55 $\mathrm{V}$ (half-peak width $60 \mathrm{mV}$ )) (Fig. 4) shows no significant splitting of the redox peaks of the ferricenium/ ferrocene couple, and therefore no significant electronic coupling between different ferrocene units.

There are additionally, two redox couples (IV,V) between $1.0 \mathrm{~V}$ and $1.4 \mathrm{~V}$ (Figs. 1 and 4, Table 1). The difference between $\mathrm{IV}$ and $\mathrm{I}$ is $1.84 \mathrm{~V}$, which compares to the difference of $1.80 \mathrm{~V}$ between the first-step reduction and the first-step oxidation for metal-free tetraneopentoxy phthalocyanine [33]; therefore it is reasonable to assign IV to the first-step oxidation of phthalocyanine ring [34], forming $[\mathrm{TFC}+) \mathrm{Pc}(-1)$ $\left.\mathrm{H}_{2}\right]^{5+}$. The intervening oxidation of the ferrocene units apparently has little or no effect upon the oxidation potential of the $\mathrm{Pc}(-2)$ ring even though the formal charge of the molecule has been increased by +4 . This further indicates the lack of coupling of the ferrocene units through the phthalocyanine $\pi$-framework.

The difference between IV and $V$ is only $0.07 \mathrm{~V}$, so $\mathrm{V}$ cannot be the second-step phthalocyanine ring oxidation to $\mathrm{Pc}(0)[33,34]$. Ring oxidized $\mathrm{Pc}(-1)$ species are 
$\lceil 0.1 \mu \mathrm{A}$

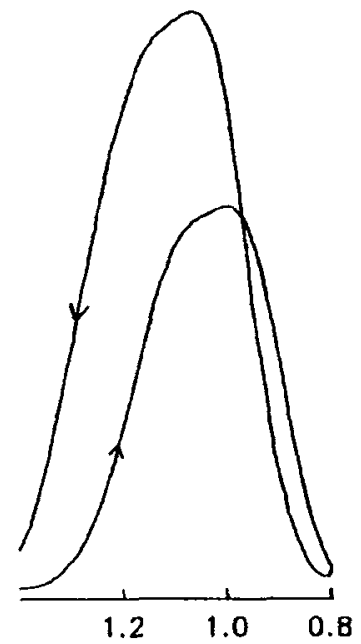

$\lceil 0.5 \mu \mathrm{A}$

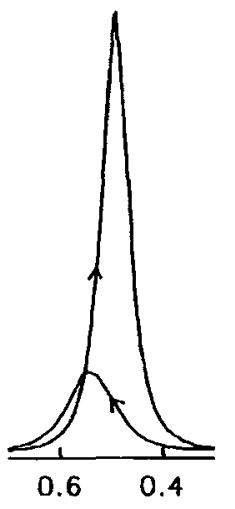

$[0.1 \mu \mathrm{A}$

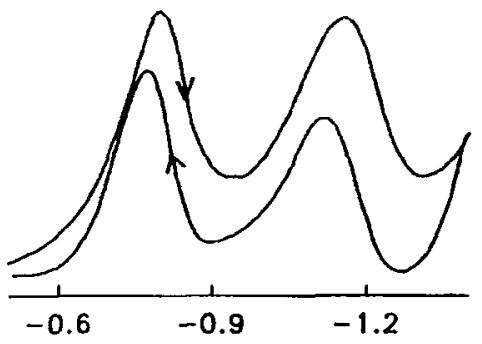

$E / V$ vs. SCE

Fig. 4. Differential pulse voltammetry of $\mathrm{TFCPC}(-2) \mathrm{H}_{2}$ over regions of redox processes $\mathrm{V}$ and IV (Left), III (Middle) and II and I (Right). Scan rate $5 \mathrm{mV}^{-1} \mathrm{~s}$, amplitude $25 \mathrm{mV}$, in DCE $/ 0.1 \mathrm{M} \mathrm{TBAPF}_{6}$, $\left[\mathrm{TFCPC}(-2) \mathrm{H}_{2}\right]=c a, 0.04 \mathrm{mM}$, at a $0.25 \mathrm{~cm}^{2}$ platinum grid electrode. Arrows indicate direction of scanning.

known to dimerize [37-39], and hence we are probably observing oxidation of mononuclear and binuclear species.

\subsection{Spectroelectrochemistry of $\mathrm{TFCPC}(-2) \mathrm{H}_{2}$}

\subsubsection{Electronic spectra of $T F c P c(-2) \mathrm{H}_{2}$ in $D C E$} solution

For mononuclear metal-free phthalocyanine, the symmetry is $D_{2 h}$ and there are two strong sharp bands in the $650-720 \mathrm{~nm}$ region, accompanied by two weaker vibrational components to higher energy of the main absorption $[40,41]$.

Figure 5 shows electronic absorption spectra of $\mathrm{TFcPc}(-2) \mathrm{H}_{2}$ in DCE at different concentrations. The shape of the spectrum is quite different from other mononuclear metal-free phthalocyanines. There are two small shoulders in addition to two major broad absorptions in the $Q$ band instead of sharp bands. The lower energy $Q$ band maximum lies at $734 \mathrm{~nm}$, substantially red shifted compared with that of other metal-free phthalocyanine species $[33,41]$. Evidently the conjugation of the four ferrocenyl groups with the phthalocyanine ring does perturb and stabilize some of the excited state levels of the TFcPc $(-2) \mathrm{H}_{2}$ molecule.

TFcPd $(-2) \mathrm{H}_{2}$ does not follow Beer's law behaviour in DCE between $6 \times 10^{-6} \mathrm{M}$ and $1 \times 10^{-4} \mathrm{M}$. At low concentration, the peak at $660 \mathrm{~nm}$ is weaker than that at $734 \mathrm{~nm}$, but with increasing concentration the ab- sorption intensity at $660 \mathrm{~nm}$ increases faster than the absorption at $734 \mathrm{~nm}$ and is shifted to $650 \mathrm{~nm}$ (Fig. 5). These phenomena indicate that $\mathrm{TFcPc}(-2) \mathrm{H}_{2}$ aggre-

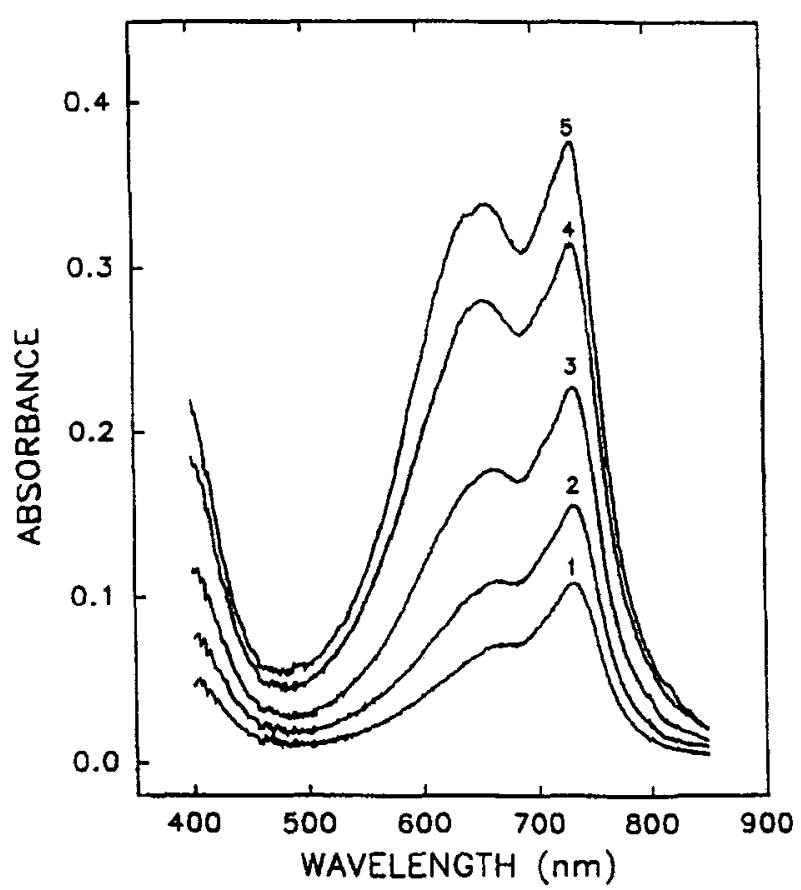

Fig. 5. Electronic absorption spectra of $\mathrm{TFcPC}-2) \mathrm{H}_{2}$ at different concentrations. Solvent: DCE; (1)0.006, (2)0.01, (3)0.02, (4)0.04, (5) $0.06 \mathrm{mM} \mathrm{TFcPd}-2) \mathrm{H}_{2}$ 


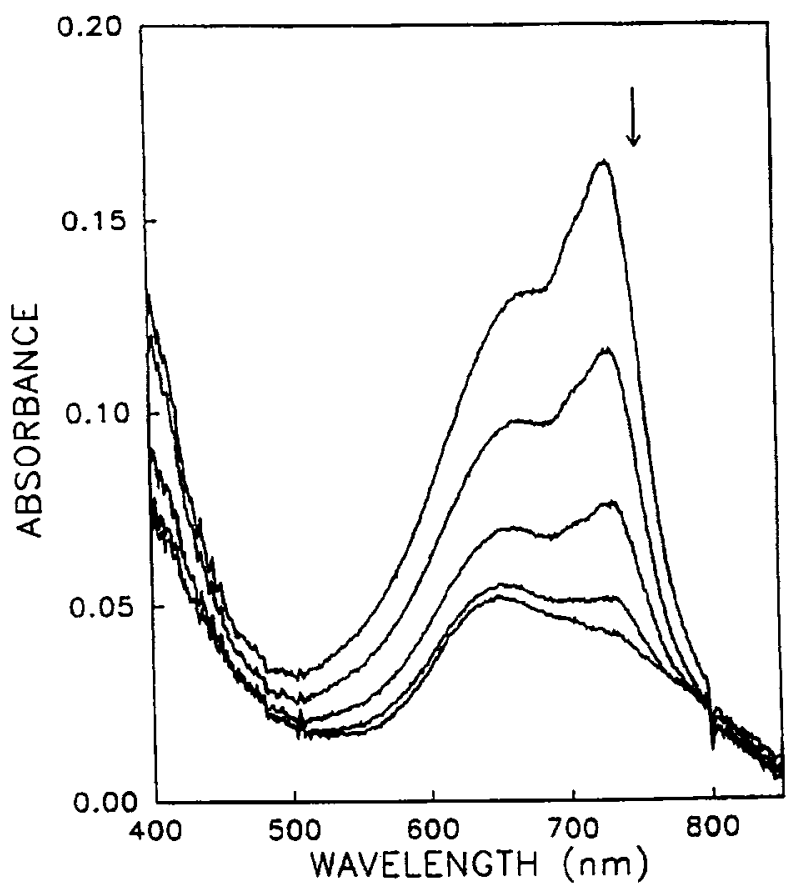

Fig. 6. Electronic spectra showing the oxidation of $\mathrm{TFCPC}(-2) \mathrm{H}_{2}$ to $\left[\mathrm{TFC}(+) \mathrm{Pc}(-2) \mathrm{H}_{2}\right]^{4+}$. The platinum electrode is polarized at $0.8 \mathrm{~V}$. Spectra presented at $40 \mathrm{~s}$ time intervals.

gates in solution, a common phenomenon for phthalocyanine species both in organic and aqueous phase $[32,41-45]$. This aggregation is probably responsible for the rather broad electrochemical oxidation wave (III).

3.2.2. The spectra of oxidized and reduced $\mathrm{TFcPc}(-2) \mathrm{H}_{2}$ species

3.2.2.1. Oxidation products. $\mathrm{TFcPc}(-2) \mathrm{H}_{2}$ was potentiostatically oxidized at $0.8 \mathrm{~V}$. Figure 6 shows the change of the electronic spectrum of TFcPc $(-2) \mathrm{H}_{2}$ during the oxidation process. Deposition of product occurs on the electrode, and the final spectrum is consistent with the transmission spectrum of a heavily aggregated $\mathrm{TFcPc}(-2) \mathrm{H}_{2}$ species, the blue edge of the $\mathrm{Q}$ band being more intense than the red $[45,46]$. The effect of the $\mathrm{Fc}^{+}$chromophore on the final spectrum is minimal because the extinction coefficient of the ferrocene species is far smaller than that of phthalocyanine.

3.2.2.2. Reduction products. When the platinum grid electrode is polarized at $-0.9 \mathrm{~V}, \mathrm{TFcPc}(-2) \mathrm{H}_{2}$ is one-electron reduced to form the $\left[\mathrm{TFCPC}(-3) \mathrm{H}_{2}\right]^{-}$ anion (Fig. 1); the spectroscopic changes accompanying the process are shown in Fig. 7. When $\mathrm{TFcPc}(-2) \mathrm{H}_{2}$ is reduced, the peak at $734 \mathrm{~nm}$ decreases, and there

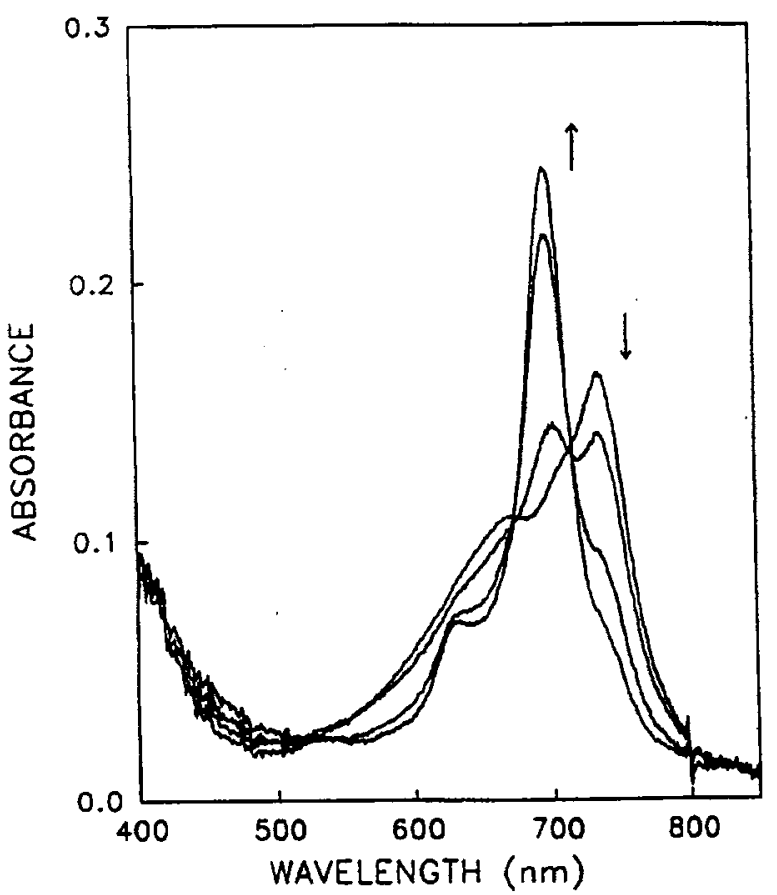

Fig. 7. Electronic spectra showing the one-electron reduction of $\mathrm{TFcPc}(-2) \mathrm{H}_{2}$ to form $\left[\mathrm{TFcPc}(-3) \mathrm{H}_{2}\right]^{-}$. The platinum electrode is polarized at $-0.9 \mathrm{~V}$. Spectra presented at $40 \mathrm{~s}$ time intervals.

appears a very strong absorption at $699 \mathrm{~nm}$ and a relatively strong peak at $630 \mathrm{~nm}$ (Table 2). Normally one expects to observe a double Q-band for a $\mathrm{Pc}(-3)$ species [47-50]. However, in this case a single $Q$ band spectrum apparently similar to that of a metallated phthalocyanine, is obtained.

Rollmann and Iwamoto [49] also reported a similar result when tetrasulfonated metal-free phthalocyanine was one-electron reduced. It was mentioned that there might be a symmetry change from $D_{2 h}$ to $D_{4 h}$ because of the substitution of central hydrogens by cations of supporting electrolyte. However, this is not the case. A similar result was observed with the reduction of the metal-free triazabenzporphyrin [38], and magnetic circular dichroism data for this species indicate that the pair of excited states which usually give rise to the

TABLE 2. Electronic absorption of TFCPC -2$) \mathrm{H}_{2}$ species in DCE

\begin{tabular}{ll}
\hline Species & $\lambda_{\max }, \mathrm{nm}\left(\epsilon, \mathrm{M}^{-1} \mathrm{~cm}^{-1}\right)$ \\
\hline$\left[\mathrm{TFcPc}(-4) \mathrm{H}_{2}\right]^{-2}$ & $660(41000), 606(53000), 505(47900)$ \\
{$\left[\mathrm{TFCPC}(-3) \mathrm{H}_{2}\right]^{-1}$} & $669(86100), 630(21100)$ \\
$\mathrm{TFcPc}(-2) \mathrm{H}_{2}{ }^{\mathrm{a}}$ & $734(57000), 660(38800)$ \\
{$\left[\mathrm{TFC}^{+} \mathrm{Pc}(-2) \mathrm{H}_{2}\right]^{+4}$} & $650(23900), 734(21100)$ \\
\hline
\end{tabular}

$0.02 \mathrm{mM} \mathrm{TFCPC}(-2) \mathrm{H}_{2}$, DCE, $0.1 \mathrm{M} \mathrm{TBAPF}_{6}{ }^{\mathrm{a}}$ Aggregated species.

${ }^{b}$ Transmission spectrum of solid deposited on an optically thin electrode. 


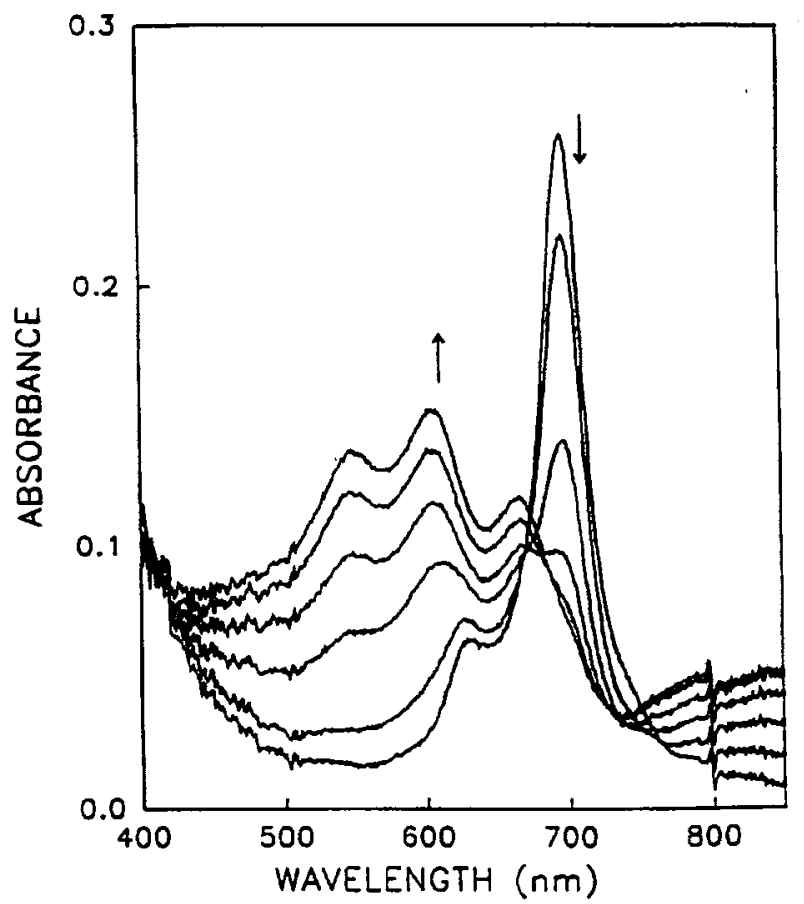

Fig. 8. Electronic spectra showing the reduction, at $-1.4 \mathrm{~V}$ of $\left[\mathrm{TFcPo}(-3) \mathrm{H}_{2}\right]^{-}$to form $\left[\mathrm{TFcPc}(-4) \mathrm{H}_{2}\right]^{2-}$. Spectra presented at $40 \mathrm{~s}$ time intervals.

Q-band doubling in these $\mathrm{Pc}(-3)$ species, is still present, but the states are too close together to be resolved [51].

The $\left[\mathrm{TFcPc}(-3) \mathrm{H}_{2}\right]^{-}$anion is further reduced at $-1.4 \mathrm{~V}$, to form the $\left[\mathrm{TFCPc}(-4) \mathrm{H}_{2}\right]^{2-}$ dianion, with spectroscopic changes shown in Fig. 8. The characteristic absorption peak at $699 \mathrm{~nm}$ (one-electron reduced products) disappears and is replaced by three relatively strong absorption bands at 550, 606, and $669 \mathrm{~nm}$, characteristic of $\mathrm{Pc}(-4)$ dianions (Table 2) $[40,50]$. Both the tri- and tetra-anion may be electrochemically re-oxidized back to the starting material, TFc$\mathrm{Po}(-2) \mathrm{H}_{2}$.

\section{Summary}

In the tetraferrocenylphthalocyanine species, there is no coupling between the ferrocene units in the ground state, and the four ferrocene units are oxidized at the same potential. From the shift in the $Q$ band in the metal-free species, there is some evidence for interaction of the ferrocene units with the phthalocyanine $\pi$-system in the excited state. Reduction of this species leads to the usual formation of a $\mathrm{Pc}(-3)$ anion and $\mathrm{Pc}(-4)$ dianion whose spectra show no special perturbation resulting from the presence of ferrocene units.

\section{Acknowledgments}

We are indebted to the Natural Sciences and Engineering Research Council (Ottawa) and the Office of Naval Research (Washington) for financial support. Mr. Z. Jin is indebted to Mr. H. Masui for technical assistance.

\section{References}

1 A.B.P. Lever, M.R. Hempstead, C.C. Leznoff, W. Liu, M. Melnik, W.A. Nevin and P. Seymour, Pure Appl. Chem., 58 (1986) 1467.

2 J.W. Buckler, (ed.), Metal Complexes with Tetrapyrrole Ligands. I. Structure and Bonding, Springer, Berlin, 1987, Vol. 64.

3 M.A. Petit, T. Thami and R. Even, J. Chem. Soc., Chem. Commun., 15 (1989) 1059.

4 S. Palacin, A. Ruaudel-Teixier and A. Barraud, J. Phys. Chem., 93 (1989) 7195.

5 N. Harron, J. Coord. Chem., 19 (1988) 25.

6 A.B.P. Lever, Chemtech., August (1987) 506.

7 T. Hirai and J. Yamaki, J. Appl. Electrochem., 15 (1985) 77.

8 J. Silver, P.J. Lukes, P.K. Hey and J.M. O'Conner, Polyhedron, 8 (1989) 1631.

9 S. Maroie, M. Savy and J.J. Verbist, Inorg. Chem., 18 (1979) 2560.

10 N. Furuya and K. Matsui, J. Electroanal. Chem., 271 (1989) 181.

11 M.V. Rosenthal, T.A. Skotheim and C.A. Linkous, Synth. Met., 15 (1986) 219.

12 C.S. Choi and M. Tachikawa, J. Am. Chem. Soc., 112 (1990) 1757.

13 N. Doddapaneni, Proc. 30th Power Sources Symp., (1984) 411.

14 N. Doddapaneni, Proc. 31th Power Sources Symp., (1986) 508.

15 P. Shu, K. Bechgaard and D.O. Cowan, J. Org. Chem., 41 (1976) 1849.

16 W.H. Morrison, Jr., S. Krogsrud and D.N. Hendrickson, Inorg. Chem., 12 (1973) 1998.

17 H. Scholl and K. Sochaj, Electrochim Acta, 36 (1991) 689.

18 E.S. Schmidt, T.S. Calderwood and T.C. Bruice, Inorg. Chem., 25 (1986) 3718

19 R.G. Wollmann and D.N. Hendrickson, Inorg. Chem., 16 (1977) 3079.

20 K.M. Kadish, Q.Y. Xu and J.-M. Barbe, Inorg. Chem., 26 (1987) 2566.

21 P.D. Beer, M.G.B. Drew, A. Ibbotson and E.L. Tite, J. Chem. Soc., Chem. Commun, (1988) 1498.

22 (a) P.D. Beer and E.L. Tite, Tetrahedron Lett., (1988) 2349; (b) P.D. Beer, E.L. Tite and A. Ibbotson, J. Chem. Soc., Chem. Commun., (1989) 1874.

23 P.D. Beer, A.C. Smythe, E.L. Tite and A. Ibbotson, J. Organomet. Chem., 376 (1989) C11.

24 (a) P.D. Beer, E.L. Tite, M.G.B. Drew and A. Ibbotson, J. Chem. Soc., Dalton Trans., (1990) 2543; (b) P.D. Beer, A.D. Keefe, V. Bohmer, H. Goldmann, W. Vogt, S. Lecocq and M. Perin, $J$. Organomet. Chem., 421 (1991) 265.

25 P.D. Beer, O. Kocian and R.J. Mortimer, J. Chem. Soc., Dalton Trans., (1990) 3283.

26 G. De Santis, L. Fabbrizzi, M. Licchelli and P. Pallavicini, Coord. Chem. Rev., 120 (1992) 237.

27 J.B. Flanagan, S. Margel, A.J. Bard and F.C. Anson, J. Am. Chem. Soc., 100 (1978) 4248.

28 M. Rosenblum, W.G. Howells, A.K. Banerjee and C. Bennett, J. Am. Chem. Soc., 84 (1962) 2726. 
29 S.M. Marcuccio, P.I. Svirskaya, S. Greenberg, A.B.P. Lever, C.C. Leznoff and K.B. Tomer, Can. J. Chem., 63 (1985) 3057.

30 R.P. Linstead and A.R. Lowe, J. Chem. Soc., (1934) 1022; P.A. Barrett, D.A. Frye and R.P. Linstead, J. Chem. Soc., (1938) 1157.

31 X.Q. Lin and K.M. Kadish, Anal. Chem., 58 (1986) 1493.

32 D.W. Clack, N.S. Hush and I.S. Woolsey, Inorg. Chim. Acta, 19 (1976) 129.

33 G. Fu, Y. Fu, K. Jayaraj and A.B.P. Lever, Inorg. Chem., 29 (1990) 4090.

34 A.B.P. Lever, in C.C. Leznoff and A.B.P. Lever (ed.) Phthalocyanines: Properties and Applications, VCH, Vol. 3, 1993, p.1.

35 A.J. Bard and L.J. Faulkner, Electrochemical Methods, Wiley, New York, 1980.

$36 \mathrm{H}$. Scholl and K. Sochaj, Electrochim Acta, 36 (1991) 689.

37 (a) E. Ough, T.Z. Gasyna and M.J. Stillman, Inorg. Chem., 30 (1991) 2301; (b) T. Nyokong, T.Z. Gasyna and M.J. Stillman, Inorg. Chem, 26 (1987) 548.

38 Y.H. Tse, A. Goel, M. Hu, C.C. Leznoff, J.E. Van Lier and A.B.P. Lever, Can. J. Chem., 71 (1993) 742.

39 (a) G.W. Rayner Canham, J. Myers and A.B.P. Lever, Chem. Comm., (1973) 483; (b) J.F. Myers, G.W. Rayner Canham and A.B.P. Lever, Inorg. Chem., 14 (1975) 461.

40 M. Gouterman, J. Chem. Phys., 30 (1959) 1139.
41 M.J. Stillman in C.C. Leznoff and A.B.P. Lever (eds.) Phthalocyanines: Properties and Applications, VCH, Vol. 1, 1989, p.133.

42 A.B.P. Lever, Adv. Inorg. Chem. Radiochem., 7 (1965) 27.

43 Z.A. Schelly, R.D. Farina and E.M. Eyring, J. Phys. Chem., 74 (1970) 617.

44 E.W. Abel, J.M. Pratt and R. Whelan, J. Chem. Soc., Dalton. Trans., (1976) 509.

45 E.S. Dodsworth, A.B.P. Lever, P. Seymour and C.C. Leznoff, J. Phys. Chem., 89 (1985) 5698.

46 M. Kasha, H.R. Rawls and M.A. El-Bayoumi, Pure Appl. Chem., Il (1965) 371.

47 P.C. Minor, M. Gouterman and A.B.P. Lever, Inorg. Chem., 24 (1985) 1894.

48 J. Mack, S. Kirkby, E.A. Ough and M.J. Stillman, Inorg, Chem., 31 (1992) 1717

49 L.D. Rollmann and R.T. Iwamoto, J. Am. Chem. Soc., 90 (1968) 1455.

50 M.J. Stillman, in C.C. Leznoff and A.B.P. Lever (eds.) Phthalocyanines: Properties and Applications, VCH, New York, Vol. 3, 1993, p.277.

51 M.J. Stillman, E.A. Ough, N. Kobayashi and A.B.P. Lever, in preparation. 